\title{
Extra and Intramedullary Anaplastic Ependymoma in Thoracic Spinal Cord
}

\author{
Byung Soo Kim¹, Sang Woo Kim¹, Kyung-Woo Kwak', Jun Huck Choi ${ }^{2}$ \\ Departments of Neurosurgery ${ }^{\prime}$, Pathology ${ }^{2}$, Yeungnam University, College of Medicine, Daegu, Korea
}

Spinal ependymoma occupies $40-60 \%$ of primary spinal cord tumors and has a feature of intramedullary tumor. The tumor most commonly arises from the central canal of the spinal cord, the conus medullaris or the filum terminale and its pathological features are usually benign. Unlike above characteristics, intra and extramedullary ependymomas are reported very rarely and have wide variety of histological features. We present a rare case of spinal anaplastic ependymoma with an accompanied exophytic lesions extramedullary as well. The tumor was poorly delineated between a spinal cord and the extramedullary components in operative view. After we had confirmed the frozen biopsy as anaplastic ependymoma, the remnant mass embedded in the spinal cord was remained because of its unclear resection margin and the risk of neurological deterioration. She underwent radiotherapy with $50.4 \mathrm{~Gy}$, and there were newly developed mass lesions at the lumbosacral region on the MRI, 14 months postoperatively.

Key Words: Ependymoma $\cdot$ Exophytic $\cdot$ Intradural extramedullary

\section{INTRODUCTION}

Spinal cord ependymoma, that is one of spinal cord glioma, is a slow growing tumor emerging from cells lining of central canal within the spinal $\operatorname{cord}^{1,7,9)}$. They account for $60 \%$ of all intramedullary tumors ${ }^{2,12)}$ and their histopathological classification includes myxopapillary ependymoma (WHO grade I), subependymoma (WHO grade I), ependymoma (WHO grade II) and anaplastic ependymoma (WHO grade III $)^{14,24)}$. Ependymoma is usually presented as intramedullary tumor of spinal cord, however coexisting of intradural extramedullary (IDEM) components of spinal ependymoma is very rare. Most tumors located in the intradural extramedullary portion are schwannoma or meningioma, so ependymoma is not even considered in the differential diagnosis of IDEM spinal tumors ${ }^{21)}$. According to the previous reports, there were 21 cases of primary IDEM ependymomas and 5 cases of exophytic ependymomas ${ }^{11)}$. In this article, we report a rare case of thoracic anaplastic ependymoma with an exophytic component.

\footnotetext{
- Received: May 15, 2013 - Revised: July 20, 2013

- Accepted: July 22, 2013

Corresponding Author: Sang Woo Kim, MD

Department of Neurosurgery, Yeungnam University, College of Medicine,

317-1 Daemyung-dong, Nam-gu, Daegu 705-717, Korea

Tel: +82-53-620-3790, Fax: +82-53-620-3770

E-mail: sw902@ynu.ac.kr
}

\section{CASE REPORT}

A 48-year-old woman had experienced a radiating pain on both legs for 6 months. For 1 month before visiting our department, a radiating pain was getting worse and she recognized newly developed lower extremity motor weakness and urinary incontinence. She underwent magnetic resonance imaging (MRI) that showed suspicious IDEM spinal mass which was well-enhanced on T1-weighted image with contrast and isosignal intensity on T2-weighted image at T7-T9. There were also intramedullary component and cord edema at T9-T10. The mass lesion was well-enhanced under gadolinium administration displacing the cord to opposite side severely (Fig. 1, 2). There was no evidence of mass lesion in the other site of central nervous system.

We planned the total resection of the intra and extramedullary mass lesions under the laminectomy. When the dura mater was opened, a dark-pink colored and encapsulated extramedullary component of the tumor was observed. The compressed spinal cord was displaced to right side and there were severe adhesion and ill-defined interface between the extramedullar mass and spinal cord. Under microscope, we removed extramedullary component totally, dissected the arachnoid layer around the cord connecting to extramedullary component and attempted to remove the intramedullary component in the spinal cord. However, we stopped resection 

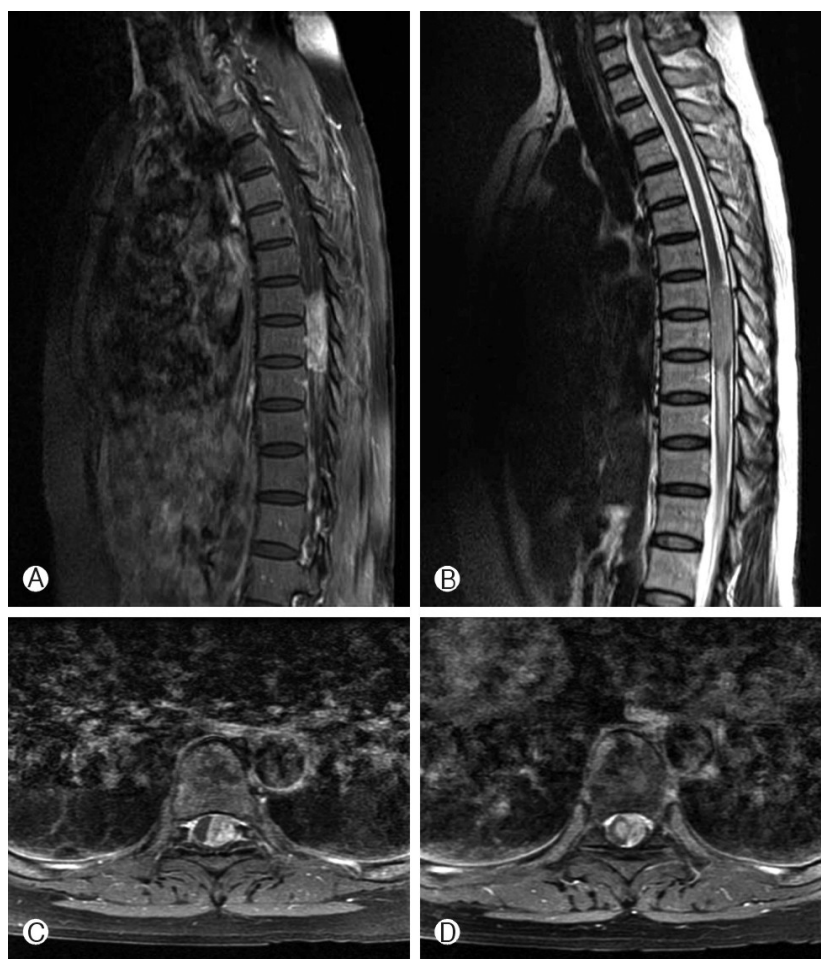

Fig. 1. Preoperative spinal MRI. (A) T1-weighted sagittal MRI with the contrast showing an oval shaped enhanced mass at T7-9. (B) T2-weighted sagittal MRI showing a mass with slightly high signal intensity at T7-9 and cord signal change at T9-11. (C) T1-weighted axial MRI with the contrast showing an enhanced mass displacing the cord to right side at T8. (D) T1-weighted axial MRI with the contrast showing an enhanced mass displacing the cord to oppo site side and an enhanced small round shape mass within the cord is presented at T9.

and left the residual portion of mass lesion on the cord with concern for the risk of neurological deterioration and intraoperative frozen biopsy of the extramedullary component.

Histological examination revealed a sort of high grade glial tumor. The cells were characterized by high cellularity and nuclear pleomorphism (Hematoxylin-Eosin stain, $\times 200$ ) and there were perivascular pseudorosettes and microvascular proliferations. The cells presented immunoreactivity for glial fibrillary acidic protein (GFAP) and the S100, but negative for epithelial membrane antigen (EMA) and CD34 (Fig. 3). Ki-67 index was approximately $40 \%$. The final diagnosis was anaplastic ependymoma, WHO grade III.

Postoperatively, the patient's neurological condition was improved in a lower extremity motor weakness except urinary incontinence. Six weeks after operation, she was planned to perform radiotherapy with $1.8 \mathrm{~Gy}$ in 28 fractions and total came to $50.4 \mathrm{~Gy}$. There was recurrence of the tumor at the ventral epidural space with remnant component at the spinal cord of T8 level on the follow-up MRI just before the initiation
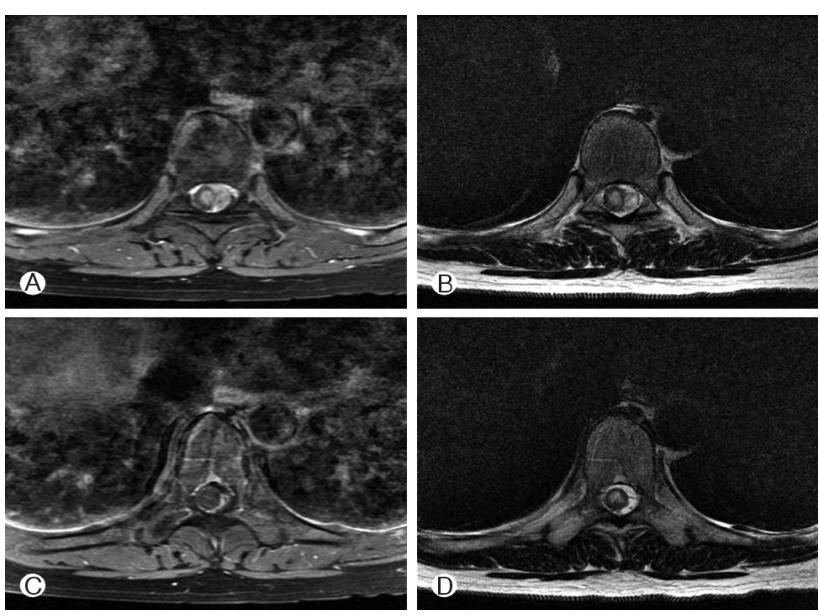

Fig. 2. Preoperative axial MRI showing mass lesion and intramedullary edema. (A) and (C) are T1-weighted images with contrast, (B) and (D) are T2-weighted images. (A) and (B) showing enhanced extramedullary mass lesion and enhanced component with edematous changes on the spinal cord at T7. (C) and (D) showing a spinal cord at T9 below extramedullary mass, there are high signal intensity on T2-weighted image and iso-signal intensity on $\mathrm{Tl}$-weighted image with contrast which regarded as an intramedullary edematous changes, not a mass lesion.
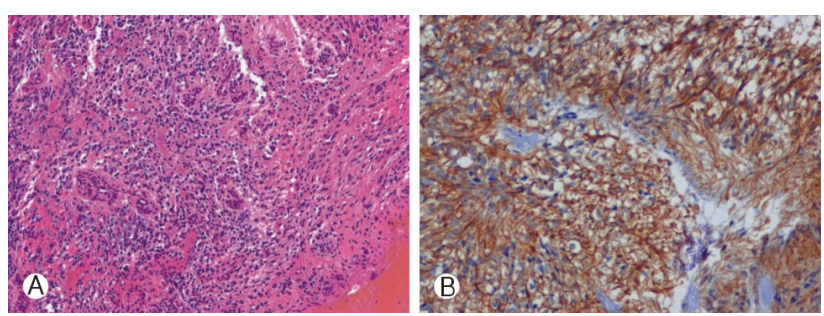

Fig. 3. Photomicrographs. (A) The tumor cells are characterized by high cellularity and nuclear pleomorphism (Hematoxylin-Eosin stain, $\times 200$ ). There are perivascular pseudorosettes and microvascular proliferations. (B) The cells showed positive reaction for glial fibrillary acidic protein (GFAP) (Immunohistochemical stain, $\times 200$ ).

of radiotherapy. The mass lesions of T8 level were disappeared and spinal cord atrophy was found on the follow-up MRI after radiotherapy. However, the patient's neurologic condition of the lower extremities was deteriorated again and there were newly developed mass lesions at the lumbosacral region on the MRI, 14 months postoperatively. It might be CSF dissemination. We recommend further treatment, but she refused.

\section{DISCUSSION}

Spinal ependymoma is almost presented as intramedullary tumor, and primary IDEM and exophytic ependymoma are rare. 
It is thought that the spinal primary IDEM ependymoma may arise from heterotopic ependymal cells which were left in the intradural extramedullary space when the neural tube closes $^{6,7,19,21)}$. This hypothesis is supported by the following Cooper's descriptions ${ }^{6,7,19,21)}$ : (1) lack of an apparent attachment to the central nervous system, (2) absence of a primary neoplastic process within the brain or spinal cord, (3) the encapsulated appearance, location along the neuraxis and frequent association with congenital anomalies. The review of 21 cases of IDEM ependymoma ${ }^{11)}$ shows the ages ranging from 24 to 69 years old with female predominance ${ }^{3,4,17,19)}$. The hormonal theory was proposed by Duffau et al. ${ }^{7}$, but it was not confirmed by any cytogenic or molecular study. Thoracic spine is the most common location for spinal IDEM ependymoma in contrast to intramedullary ependymoma that mainly affect the cervical spinal cord, the conus medullaris and filum terminale regions, 3,22 .

Intramedullary ependymoma with an exophytic component to IDEM space is very rare. There were only 5 reports about $\mathrm{it}^{20)}$. Subependymoma, however, has a marked tendency to grow eccentrically within the cord or to show an exophytic component. The histogenesis of subependymoma has been a matter of debate over years, but it is currently thought that they may represent a variant of ependymoma ${ }^{15,16,23)}$. The tumor has a tendency to originate from the ependymal cells of the central canal, rather than from the IDEM space. It is highly improbable that the tumor grew into the spinal cord from outside of it. As tumors of brain stem and spinal cord grow along the path of least resistance, exophytic ependymoma of the spinal cord may grow longitudinally along the sensory and motor tracts or transversely along the root entry zone ${ }^{8,23)}$.

The intraoperative findings of primary IDEM ependymoma had shown well-circumscribed and encapsulated tumors that can be easily removed from the surface of the spinal cord. In the case of exophytic ependymoma, mid portion of the tumor arise from an intramedullary component and has not a clear dissection plane from the spinal $\operatorname{cord}^{20}$. However, exceptional cases were also reported that a thin stalk between tumor and spinal cord could be easily amputated by Kinsman et al. ${ }^{18)}$ and its pathological feature was WHO grade III. Moreover, primary IDEM ependymomas infiltrating arachnoid membrane were noted by Graca et al. ${ }^{10)}$ and Iunes et al. ${ }^{17}$. Abundant vascular infiltration into the pia mater was also reported by Robels et al. ${ }^{22)}$ and Guppy et al. ${ }^{11)}$ Their pathological findings were $\mathrm{WHO}$ grade III. Although the possibilities that tumor invades into the spinal cord from outside of it in high grade pathology, there were no reports to offer definite evidences on neither operation field nor MRI until now.

In our case, an enhanced mass with an oval shape at T7-9 and a cord signal change at T9-11 were presented on MRI (Fig.
1-A, B). The interface between mass lesion and spinal cord was ill-defined, and a small suspicious intramedullary mass connected with IDEM component was noted on T1- weighted axial MRI with contrast (Fig. 1-C, D). The cord was displaced to the opposite side by IDEM component, T1- weighted axial image with contrast and T2-weighted image differentiate edematous changes from mass lesion on the spinal cord (Fig. 2). The disturbed venous outflow such as venous stasis caused by mass volume effect produces edematous change presented by a high signal intensity on $\mathrm{T} 2$-weighted image ${ }^{13)}$. This finding was a peritumoral edema, which is usually found on the typical intramedullary tumor ${ }^{5}$, this could be a clue implying the exophytic ependymoma. The extramedullary component was large and its histopathological finding was anaplastic ependymoma, $\mathrm{WHO}$ grade III.

We thought the possibility that primary IDEM spinal ependymoma with high WHO grade may spread into the intramedullary space at first. However, the shape of intramedullary component was round and smooth not enough to explain invasion from outside, and there were only amount of leptomeningeal invasion like that of high grade tumor in the previous reports. So we concluded our case as the exophytic ependymoma developed intramedullary and spread out extramedullary.

\section{CONCLUSION}

Spinal ependymoma is usually located intramedullary and benign pathology. We report a rare case of anaplastic ependymoma with an exophytic component of the thoracic spine. The existence of the enhanced intramedullary component with edematous change could be an important clue to diagnose a high grade of spinal ependymoma. Radiotherapy and careful follow-up are essential after operation, because of the residual component of tumor and a high risk of dissemination or recurrence.

\section{REFERENCES}

1. Akutsu H, Shibata Y, Okazaki M, Hyodo A, Matsumura A: Intramedullary clear cell ependymoma in the cervical spinal cord: case report. Neurosurgery 47:1434-1437; discussion 14371438, 2000

2. Baleriaux DL: Spinal cord tumors. Eur Radiol 9:1252-1258, 1999

3. Benzagmout M, Boujraf S, Oulali N, Chbani L, Amarti A, Chakour $\mathrm{K}$, et al: Intradural extramedullary ependymoma: is there constantly a hormonal relationship? Surg Neurol 70:536-538; discussion 538, 2008

4. Cerase A, Venturi C, Oliveri G, De Falco D, Miracco C: Intradural extramedullary spinal anaplastic ependymoma. Case illust- 
ration. J Neurosurg Spine 5:476, 2006

5. Choi JY, Chang KH, Yu IK, Kim KH, Kwon BJ, Han MH, et al: Intracranial and spinal ependymomas: review of MR images in 61 patients. Korean J Radiol 3:219-228, 2002

6. Cooper IS, Craig WM, Kernohan JW: Tumors of the spinal cord; primary extramedullary gliomas. Surg Gynecol Obstet 92: 183-190, 1951

7. Duffau H, Gazzaz M, Kujas M, Fohanno D: Primary intradural extramedullary ependymoma: case report and review of the literature. Spine (Phila Pa 1976) 25:1993-1995, 2000

8. Epstein FJ, Farmer JP: Brain-stem glioma growth patterns. J Neurosurg 78:408-412, 1993

9. Fourney DR, Siadati A, Bruner JM, Gokaslan ZL, Rhines LD: Giant cell ependymoma of the spinal cord. Case report and review of the literature. J Neurosurg 100:75-79, 2004

10. Graca J, Gultasli N, D'Haene N, Brotchi J, Salmon I, Baleriaux D: Cystic extramedullary ependymoma. AJNR Am J Neuroradiol 27:818-821, 2006

11. Guppy KH, Hou L, Moes GS, Sahrakar K: Spinal intradural, extramedullary anaplastic ependymoma with an extradural component: Case report and review of the literature. Surg Neurol Int 2:119, 2011

12. Hanbali F, Fourney DR, Marmor E, Suki D, Rhines LD, Weinberg JS, et al: Spinal cord ependymoma: radical surgical resection and outcome. Neurosurgery 51:1162-1172; discussion 1172-1164, 2002

13. Henderson FC, Crockard HA, Stevens JM: Spinal cord oedema due to venous stasis. Neuroradiology 35:312-315, 1993

14. Henson JW: Spinal cord gliomas. Curr Opin Neurol 14:679682, 2001
15. Hentschel SJ, McCutcheon IE, Ginsberg L, Weinberg JS: Exophytic ependymomas of the spinal cord. Acta Neurochir (Wien) 146:1047-1050, 2004

16. Ishikawa T, Iwasaki Y, Isu T, Akino M, Koyanagi I, Hida K, et al: [Spinal intramedullary tumor with exophytic growth]. No Shinkei Geka 16:1339-1345, 1988

17. Iunes EA, Stavale JN, de Cassia Caldas Pessoa R, Ansai R, Onishi FJ, de Paiva Neto MA, et al: Multifocal intradural extramedullary ependymoma. Case report. J Neurosurg Spine 14:65-70, 2011

18. Kinsman MJ, Callahan JD, Hattab EM, Cohen-Gadol AA: Extramedullary spinal ependymoma: a diagnostic challenge and review of the literature. Clin Neurol Neurosurg 113:661-664, 2011

19. Moser FG, Tuvia J, LaSalla P, Llana J: Ependymoma of the spinal nerve root: case report. Neurosurgery 31:962-964; discussion 964, 1992

20. Orozco LD, Tiel RL: Exophytic ependymoma of the thoracic spine. J Clin Neurosci 18:1262-1264, 2011

21. Payer M, Yonekawa Y, Imhof HG: Solitary thoracic intradural extramedullary ependymoma. J Clin Neurosci 6:344-345, 1999

22. Robles SG, Saldana C, Boto GR, Martinez A, Zamarron AP, Jorquera $\mathrm{M}$, et al: Intradural extramedullary spinal ependymoma: a benign pathology? Spine (Phila Pa 1976) 30:E251-254, 2005

23. Venkataramana NK, Kolluri VR, Narayana Swamy KS, Jain VK, Das BS, Das S: Exophytic gliomas of the spinal cord. Acta Neurochir (Wien) 107:44-46, 1990

24. Yoo NH, Han SR, Yoon SW, Yee GT, Choi CY, Sohn MJ, et al: Spinal Intramedullary Ependymoma:-Myxopapillary Ependymoma vs. Ependymoma. Korean Journal of Spine 2, 2005 